\title{
Dynamic cross-talk between host primary metabolism and viruses during infections in plants
}

César Llave

Address

Department of Environmental Biology, Centro de Investigaciones Biológicas, Consejo Superior de Investigaciones Científicas. Ramiro de Maeztu 9, 2804-Madrid, Spain

Corresponding author: Llave, César

Phone: +34-91-837 3112 Ext. 4259

Fax: +34-91-536 0432

E-mail: cesarllave@,cib.csic.es

Word counting

Abstract: 112

Text: 2031 


\begin{abstract}
Upon infection plant viruses modulate cellular functions and resources to survive and reproduce. Plant cells in which the virus is replicating are transformed into strong metabolic sinks. This conversion gives rise to a massive reprogramming of plant primary metabolism. Such a metabolic shift involves perturbations in carbohydrates, amino acids and lipids that eventually lead to increase respiration rates, and/or decrease in photosynthetic activity. By doing so, plants provide metabolic acclimation against cellular stress and meet the increased demand for energy needed to sustain virus multiplication and defense responses against viruses. This review will highlight our current knowledge pertaining to the contribution of primary metabolism to the outcome of viral infections in plants.
\end{abstract}




\section{Introduction}

A viral infection is a highly dynamic process in which infected plant cells are transformed into major metabolic consumers (sinks) for products of photosynthesis. During the infection, nitrogen and carbon skeletons are required for the synthesis of new molecules and energy is necessary to fuel biosynthesis. The source-to-sink transition elicits reallocation and increases demands for photosynthetic assimilates, increases respiration rates, or decreases in photosynthetic activity. Such a metabolic shift contributes to sustain viral proliferation but is also necessary to activate defense mechanisms. Due to the uneven nature of viral infections in plants and that different virus-host interactions have been studied, it is complicated to depict an unequivocal generalized picture of the metabolic responses triggered by plant viruses. In addition, many reactions in central metabolism are reversible and complex, hindering the perception of major changes in metabolite levels. Nevertheless, a considerable effort has been made to elucidate alterations in metabolite contents linked to viral infections in plants of which significant commonalties arise (Figure 1). In this review, the current knowledge on the modulation of plant primary metabolism during viral infections and its importance for plant compatibility and/or resistance are discussed.

Metabolomics strategies based on chromatography, mass spectrometry (MS) or nuclear magnetic resonance (NMR) spectroscopy in combination with multivariate data analysis have provided an excellent platform to understand the input of certain metabolites in the plant's response to viral infections [1-7]. Recent studies have gone steps further by using system biology approaches to study primary metabolism in plant-virus interactions. For instance, time-course transcriptomics and GC-MS-based metabolomics supported by functional reverse genetics were used to study the reciprocal influence of primary metabolism and Tobacco rattle virus (TRV) infection in Arabidopsis thaliana [8]. GC-MS-based metabolomics and gene expression data identified altered and unique metabolic signatures characteristic of two 
tomato inbred lines that exhibited susceptibility or resistance to Tomato yellow leaf curl virus (TYLCV) [9], or in response to mild and aggressive isolates of Potato virus $Y$ (PVY) in potato leaves at different times of disease development [10].

\section{Plant virus, carbohydrate metabolism and photosynthesis}

The carbohydrate status has profound implications in mobilization and synthesis of storage compounds, symptoms development and defense functions, and its alteration is diagnostic for perturbations in photosynthesis and respiration. The accumulation of sugars in the infected tissue causes an imbalance in the ratio of nitrogen and carbon, and the sensing of such changes results in a feedback transcriptional regulation of photosynthesis genes, and occasionally, photosynthetic repression [11-17]. Even though repression of photosynthesis and induction of sink metabolism is a general response to viral infection, the effects on sugar levels varies considerably between different host-virus interactions. Changes in sugar levels involving the accumulation of enlarged starch grains in the chloroplast have been reported for some compatible interactions [18-21], whereas starch content decreases for some others [22,23]. Interestingly, viral accumulation is unaffected in starch-depleted Arabidopsis mutants suggesting that starch catabolism is not strictly required for virus multiplication in this species $[8,20]$. Metabolism of sink tissues, where sugar is used, is mainly sustained by sucrose synthesized in source leaves and transported through the phloem into sink tissues. Sucrose and soluble sugars are abundant in different host species infected with ToMV, Cauliflower mosaic virus (CaMV), and TRV [2,8,24], whereas soluble sugar contents decrease upon infection with PVY, Turnip yellow mosaic virus (TYMV), Jatropha mosaic virus (JMV), Ageratum enation virus (AEV) or Squash mosaic virus (SqMV) [5,6,10,25,26].

Changes in carbohydrates accumulation respond to different causes that include physical disturbance of the transport path (e.g. modification of plasmodesmata by viral movement 
proteins), inhibition of sugar transport proteins, induction of starch hydrolysis or cell wall invertases. Cucumber mosaic virus (CMV) increases sucrose concentration in the phloem sap of CMV-infected melon plants likely by altering sucrose localization [27]. Sucrose export routes can be severely affected by callose deposition at the cell-to-cell interfaces observed in multiple plant-virus interactions [28]. Infection of cotyledon of marrow plants by CMV causes a gradual increment of soluble sugars and a detriment of starch likely due to enhanced starch hydrolase activities [29,30]. The elevated hexose levels observed in tobacco plants infected with $\mathrm{PVY}^{\mathrm{N}}$ are concomitant with increased invertase activity, which cleaves sucrose into glucose and fructose [31]. Interestingly, cell-wall invertase-overexpressing transgenic tobacco or Arabidopsis plants accumulate large amounts of soluble sugars and are resistant against $\mathrm{PVY}^{\mathrm{N}}$ and Tobacco mosaic virus (TMV), respectively [31]. This observation suggests that high hexoses contribute to make plants less susceptible to viral infection, and highlights the relevance of the regulation of carbohydrate metabolism for defense.

\section{Plant viruses and amino acid metabolism}

Viruses are important modulators of the amino acid content in infected cells, and amino acid metabolism is critical in the plant response to infection. For instance, in tobacco, alanine, glutamine and proline levels increase in both locally infected leaves and leaves undergoing systemic acquired resistance to TMV [1]. High concentrations of individual and total amino acids have also been reported in different host species following infection with ZYMV, Papaya ringspot virus (PRSV), Bromo mosaic virus (BMV), and TRV [2,23,32,33]. Amino acids are significantly abundant at the time points of maximal viral accumulation in TRVinfected Arabidopsis, although developmental timing is the dominant source of variance in the amino acid content [8]. In potato, infection with PVY leads to an initial decrease in amino acid concentration followed by a gradual increase over time that is particularly significant in 
leaves infected with the aggressive PVY ${ }^{\mathrm{NTN}}$ isolate compared to the mild $\mathrm{PVY}^{\mathrm{N}}$ isolate [10]. Although the precise role of virus-responsive amino acids during the infection has not been elucidated, it is tempting to propose that they may participate in antiviral responses. For instance, several amino acids and intermediates of the amino acid biosynthetic pathway accumulate to higher levels in TYLCV-resistant tomato lines compared to susceptible lines [9]. In Arabidopsis, accumulation of proline is observed during the hypersensitive reaction (HR), a plant response whereby the rapid death of cells at the infection site restricts the growth and spread of pathogens to other parts of the plant. External application of proline produces HR-like cell death symptoms [34,35]. In contrast, the lht 1 (lysine histidine transporter 1) Arabidopsis mutant, which has reduced contents of alanine, glutamine and proline, shows enhanced resistance to multiple pathogens [36]. Likewise, genetic inactivation of DIN4 gene, which is critical in branched-chain amino acid (BCAA) metabolism, compromises TRV proliferation in infected plants, suggesting that BCAA metabolism contributes to plant susceptibility [8].

\section{Plant viruses and respiration}

Plant defense and stress responses induced upon viral infections implicate the up-regulation of the majority of the energy-associated networks (including the glycolysis, the oxidative pentose phosphate pathway, the TCA cycle, mitochondrial energy transport, and ATP biosynthesis) [37]. A sharp increase in respiration concomitant with reduced net photosynthetic rates has been reported in plant-virus interactions [5,22,38,39]. In this scenario, the elevated levels of carbohydrates and the increasing accumulation of amino acids during viral infections fuel the energy-generating TCA pathway to maintain high respiration rates [40]. Furthermore, several organic acids connected to the TCA cycle exhibit positive responses to plants viruses in different host species $[2,5-7,10]$. This supports the notion that 
primary metabolism is largely reconfigured during pathogen infections to satisfy the energy demand required for plant defense and, likely, virus multiplication [41].

\section{Plant viruses and polyamines}

Polyamine metabolism, including the most common putrescine, spermidine and spermine, undergoes dynamic changes with polyamine levels increasing several fold during plant-virus interactions $[42,43]$. Polyamines play a key regulatory role on virus replication $[42,44]$, and have a stimulatory effect on the in vitro translation of viral RNA [45,46]. A growing body of evidence suggests that polyamines also transduce defense responses. Elevated levels of free and conjugated putrescine and spermidine and elevated biosynthetic activities occur in TMVinfected tobacco leaves undergoing the HR response, but not in TMV-infected susceptible plants [47-50]. Yamakawa et al. [51] found that free spermine, that accumulates to high levels during the $\mathrm{HR}$ in the intercellular fluids of the necrotic lesion-forming leaves, provides resistance against TMV. Induction in polyamine biosynthetic genes and spermedineresponsive genes has been reported during CMV-elicited HR in Arabidopsis [52]. Putrescine levels are also augmented in compatible plant-virus interactions [33]. In agreement with a role in defense, high putrescine in Arabidopsis provides protection against excessive TRV proliferation, as both the $a d c 1$ and $a d c 2$ mutants impaired in putrescine biosynthesis are hypersusceptible to TRV accumulation [8]. Polyamines are also more abundant in resistant tomato cultivars to TYLCV infection than in susceptible cultivars [9]. In contrast to the above observations, putrescine concentration is reduced in plants infected with Citrus exocortis viroid (CEVd) [53].

\section{Plant viruses and lipid metabolism}


The significance of cellular lipids in viral infections has long been appreciated because lipids provide energy for metabolism, participate in multiple defense signaling cascades, and are structural components of intracellular membranes in which replication of positive strand RNA viruses take place [54-58]. Membranes of different organelles also protect the viral components from the innate immune system as well as from RNA silencing-based antiviral defense $[59,60]$. During infection, viruses interfere with lipid (i.e. sterols and phospholipids) and fatty acid (FA) metabolism and biosynthesis to promote changes in the fluidity and/or plasticity of membranes that are required for the proper formation of viral replication complexes [59,61-65]. Genetic inactivation of INO2, a transcription activator involved in phospholipid biosynthesis, reduces Tomato bushy stunt virus (TBSV) replication and inhibits the activity of the viral replicase complex in yeast model host [66]. The sterol biosynthesis genes ERG25 and ERG4 affect the replication of TBSV in yeast [67], while silencing of $N$. benthamiana SMO1 and SMO2 genes, which are orthologs of ERG25, also result in a reduction in TBSV accumulation, supporting the roles of sterols in virus replication in plants [67]. In yeast, a mutation in the $O L E 1$ gene encoding $\Delta 9$ fatty acid desaturase (Olelp) severely inhibits BMV replication [68]. In this mutant, the ER lumenal spherule-associated membranes, in which viral RNA synthesis occurs, are locally depleted in unsaturated FAs $[68,69]$. TRV stimulates the incorporation of polyunsaturated FAs (linoleic and linolenic acid) in various intermediates in the synthesis of triacylglycerols and viral TRV accumulation is reduced in fad2 Arabidopsis mutants that contain reduced levels of unsaturated FA [8]. These observations suggest that viral replication is highly sensitive to reduced unsaturated FA levels. In contrast, TRV accumulates to high levels in acc1 Arabidopsis mutants, in which the initial step in the biosynthesis of very-long chain fatty acids is partly inhibited [8]. Elevated levels of linolenic acid have been reported in tobacco leaves infected with TMV [1]. A recent study shows that the marine virus E. huxleyi virus $(\mathrm{EhV})$ induces profound transcriptome 
remodeling in the alga Emiliania huxley targeted toward FA synthesis to support viral assembly [70].

\section{Conclusions and perspectives}

Viral infections cause profound perturbations in primary metabolism. Although inferences can be made from transcriptomics and metabolomics studies, little is known about the mechanisms used by viruses to interfere with metabolism in both compatible and incompatible interactions and the manner that the metabolite content contributes to viral infection and pathogenesis. Massive reprogramming of primary metabolism aims to meet the increased demand for energy needed to sustain viral multiplication and defense responses against viruses. The emerging view, however, is that accumulation of protective metabolites serve to alleviate the cellular stress imposed by the virus. As a result, viral infections confer a stage of metabolic acclimation that enables plants to cope with other environmental stresses. For instance, CMV and BMV infection of beet and rice, respectively, improve plant tolerance to freezing and drought stress, which correlates with increased osmoprotectant and antioxidant levels in infected plants [33]. Likewise, the enhanced biosynthesis of putrescine in the compatible TRV-Arabidopsis interaction makes infected plants more tolerant to freezing stress than non-infected plants [8]. Therefore, plants benefit from the vast array of infectionassociated metabolic responses by improving their tolerance to stress.

Systems biology strategies continue to increase our understanding of the dynamic role of primary metabolism during viral infection. However, there are still many questions to answer that concern the precise roles of photosynthesis, sugar partitioning, source-to-sink regulation, respiration and photorespiration in different plant-virus interactions. Future studies should also be expanded to include the use of genetically engineered plants with altered metabolite 
levels to determine the precise function of virus-responsive metabolites in host antiviral responses or acclimation to environmental stresses.

\section{Acknowledgements}

I wish to thank the editor for the invitation to write this review, and Virginia Ruiz-Ferrer, Francisco Tenllado and José Manuel Martínez-Rivas for helpful comments. I apologize for work that was not adequately discussed or cited in this review due to space constraints. This work is supported by grant BIO2012-39973 from the Spanish Ministry of Economy and Competitiveness.

\section{References and recommended reading}

Papers of particular interest, published within the period of review, have been highlighted as:

- of special interest

•• of outstanding interest

1. Choi YH, Kim HK, Linthorst HJ, Hollander JG, Lefeber AW, Erkelens C, Nuzillard JM, Verpoorte R: NMR metabolomics to revisit the tobacco mosaic virus infection in Nicotiana tabacum leaves. $J$ Nat Prod 2006, 69:742-748.

2. Lopez-Gresa MP, Lison P, Kim HK, Choi YH, Verpoorte R, Rodrigo I, Conejero V, Belles

JM: Metabolic fingerprinting of Tomato Mosaic Virus infected Solanum lycopersicum. J Plant Physiol 2012, 169:1586-1596.

3. López-Gresa MP, Maltese F, Bellés JM, Conejero V, Kim HK, Choi YH, Verpoorte R: Metabolic response of tomato leaves upon different plant-pathogen interactions. Phytochem Anal 2010, 21:89-94. 
4. Mandala R, Kathiriac P, Psychogiosa N, Bouatraa S, Krishnamurthya R, Wisharta D, Kovalchukc I: Progeny of tobacco mosaic virus-infected Nicotiana tabacum plants exhibit trans-generational changes in metabolic profiles. Biocatal Agric Biotechnol 2012, 1:115-123.

5. Sidhu OP, Annarao S, Pathre U, Snehi SK, Raj SK, Roy R, Tuli R, Khetrapal CL: Metabolic and histopathological alterations of Jatropha mosaic begomovirusinfected Jatropha curcas L. by HR-MAS NMR spectroscopy and magnetic resonance imaging. Planta 2010, 232:85-93.

6. Srivastava S, Bisht H, Sidhu OP, Srivastava A, Singh PC, Pandey RM, Raj SK, Roy R, Nautiyal CS: Changes in the metabolome and histopathology of Amaranthus hypochondriacus L. in response to Ageratum enation virus infection. Phytochemistry 2012, 80:8-16.

7. Bazzini AA, Manacorda CA, Tohge T, Conti G, Rodriguez MC, Nunes-Nesi A, Villanueva S, Fernie AR, Carrari F, Asurmendi S: Metabolic and miRNA profiling of TMV infected plants reveals biphasic temporal changes. PLOS ONE 2011, 6:e28466.

8. Fernandez-Calvino L, Osorio S, Hernandez ML, Hamada IB, Del Toro FJ, Donaire L, Yu A, Bustos R, Fernie AR, Martinez-Rivas JM, et al.: Virus-Induced Alterations in Primary Metabolism Modulate Susceptibility to Tobacco rattle virus in Arabidopsis. Plant Physiol 2014, 166:1821-1838.

-• This work integrates transcriptomics, metabolomics and reverse genetics to study the contribution of TRV-responsive metabolic pathways to the outcome of virus infection and prove smetabolic acclimatation to stress in TRV-infected plants.

9. Sade D, Shriki O, Cuadros-Inostroza A, Tohge T, Semel Y, Haviv Y, Willmitzer L, Fernie AR, Czosnek H, Brotman Y: Comparative metabolomics and transcriptomics of 
plant response to Tomato yellow leaf curl virus infection in resistant and susceptible tomato cultivars. Metabolomics 2015, 11:81-97.

- This study reveals distinctive systemic metabolic signatures to TYLCV infection between resistant and susceptible tomato plants, including alterations in the abundance of amino acids, polyamines and defense compounds.

10. Kogovsek P, Pompe-Novak M, Petek M, Fragner L, Weckwerth W, Gruden K: Primary Metabolism, Phenylpropanoids and Antioxidant Pathways Are Regulated in Potato as a Response to Potato virus Y Infection. PLoS One 2016, 11:e0146135.

- This work studies changes in the metabolome and transcriptome of potato leaves infected with mild and aggressive isolates of PVY.

11. Reinero A, Beachy RN: Reduced Photosystem II Activity and Accumulation of Viral Coat Protein in Chloroplasts of Leaves Infected with Tobacco Mosaic Virus. Plant Physiol 1989, 89:111-116.

12. Balachandran S, Osmond CB, Makino A: Effects of Two Strains of Tobacco Mosaic Virus on Photosynthetic Characteristics and Nitrogen Partitioning in Leaves of Nicotiana tabacum cv Xanthi during Photoacclimation under Two Nitrogen Nutrition Regimes. Plant Physiol 1994, 104:1043-1050.

13. Rahoutei J, García-Luque I, Barón M: Inhibition of photosynthesis by viral infection: Effect on PSII structure and function. Physiol Plantarum 2000, 110:286-292.

14. Stare T, Ramsak Z, Blejec A, Stare K, Turnsek N, Weckwerth W, Wienkoop S, Vodnik D, Gruden K: Bimodal dynamics of primary metabolism-related responses in tolerant potato-Potato virus Y interaction. BMC Genomics 2015, 16:716.

- This work shows the dynamic changes affecting the photosynthetic apparatus upon PVY infection in potato. 
15. Seo S, Okamoto M, Iwai T, Iwano M, Fukui K, Isogai A, Nakajima N, Ohashi Y: Reduced levels of chloroplast FtsH protein in tobacco mosaic virus-infected tobacco leaves accelerate the hypersensitive reaction. Plant Cell 2000, 12:917-932.

16. Sampol B, Bota J, Riera D, Medrano H, Flexas J: Analysis of the virus-induced inhibition of photosynthesis in malmsey grapevines. New Phytol 2003, 160:403412.

17. von Schaewen A, Stitt M, Schmidt R, Sonnewald U, Willmitzer L: Expression of a yeast-derived invertase in the cell wall of tobacco and Arabidopsis plants leads to accumulation of carbohydrate and inhibition of photosynthesis and strongly influences growth and phenotype of transgenic tobacco plants. $E M B O J 1990$, 9:3033-3044.

18. Cohen J, Loebenstein G: An electron microscope study of starch lesions in cucumber cotyledons infected with tobacco mosaic virus. . Phytopathology 1975, 65:32-39.

19. Tomenius K, Oxelfelt $\mathrm{P}$ : Ultrastructure of pea leaf-cells infected with three strains of red clover mottle virus. J Gen Virol 1982, 61:143-147.

20. Handford MG, Carr JP: A defect in carbohydrate metabolism ameliorates symptom severity in virus-infected Arabidopsis thaliana. J Gen Virol 2007, 88:337-341.

21. Otulak K, Chouda M, Bujarski J, Garbaczewska G: The evidence of Tobacco rattle virus impact on host plant organelles ultrastructure. Micron 2015, 70:7-20.

22. Shalitin D, Wolf S: Cucumber mosaic virus infection affects sugar transport in melon plants. Plant Physiol 2000, 123:597-604.

- This study shows how the altered levels of carbohydrates in infected plants was accompanied by increased respiration and decreased photosynthetic rates. 
23. Blua MJ, Perring TM, Madore MA: Plant virus-induced changes in aphid population development and temporal fluctuations in plant nutrients. J Chem Ecol 1994, 20:691-707.

24. Love AJ, Martin T, Graham IA, Milner JJ: Carbohydrate partioning and sugar signalling in Cauliflower mosaic virus-infected turnip and Arabidopsis. Phys Mol Plant Pathol 2005, 67:83-91.

25. Bedbrook JR, Matthews RE: Changes in the flow of early products of photosynthetic carbon fixation associated with the replication of TYMV. Virology 1973, 53:84-91.

26. Magyarosy AC, Buchanan BB, Schurmann P: Effect of a systemic virus infection on chloroplast function and structure. Virology 1973, 55:426-438.

27. Herbers K, Takahata Y, Melzer M, Mock HP, Hajirezaei M, Sonnewald U: Regulation of carbohydrate partitioning during the interaction of potato virus $\mathrm{Y}$ with tobacco. Mol Plant Pathol 2000, 1:51-59.

28. De Storme N, Geelen D: Callose homeostasis at plasmodesmata: molecular regulators and developmental relevance. Front Plant Sci 2014, 5:138.

29. Tecsi LI, Maule AJ, Smith AM, Leegood RC: Metabolic alterations in cotyledons of Cucurbita pepo infected with Cucumber mosaic virus. $J$ Exp Bot 1994, 45:15411551.

30. Tecsi LI, Smith AM, Maule AJ, Leegood RC: A Spatial Analysis of Physiological Changes Associated with Infection of Cotyledons of Marrow Plants with Cucumber Mosaic Virus. Plant Physiol 1996, 111:975-985.

31. Herbers K, Meuwly P, Frommer WB, Metraux JP, Sonnewald U: Systemic Acquired Resistance Mediated by the Ectopic Expression of Invertase: Possible Hexose Sensing in the Secretory Pathway. Plant Cell 1996, 8:793-803. 
32. Wijeendra WAS, Ranaweera SS, Salim N: The effect of Papaya ringspot virus infection on the nitrogen metabolism of Carica papaya L.: Part II. Composition of free amino acids in the leaves. Vidyodaya J of Sci 1995, 5:131-138.

33. Xu P, Chen F, Mannas JP, Feldman T, Sumner LW, Roossinck MJ: Virus infection improves drought tolerance. New Phytol 2008, 180:911-921.

- This excellent study shows that virus infection improves plant tolerance to abiotic stress by increasing the levels of osmoprotectant and antioxidant compounds in infected plants.

34. Deuschle K, Funck D, Forlani G, Stransky H, Biehl A, Leister D, van der Graaff E, Kunze $\mathrm{R}$, Frommer WB: The role of [Delta]1-pyrroline-5-carboxylate dehydrogenase in proline degradation. Plant Cell 2004, 16:3413-3425.

35. Fabro G, Kovacs I, Pavet V, Szabados L, Alvarez ME: Proline accumulation and AtP5CS2 gene activation are induced by plant-pathogen incompatible interactions in Arabidopsis. Mol Plant Microbe Interact 2004, 17:343-350.

36. Liu G, Ji Y, Bhuiyan NH, Pilot G, Selvaraj G, Zou J, Wei Y: Amino acid homeostasis modulates salicylic acid-associated redox status and defense responses in Arabidopsis. Plant Cell 2010, 22:3845-3863.

37. Less $\mathrm{H}$, Angelovici $\mathrm{R}$, Tzin V, Galili G: Coordinated gene networks regulating Arabidopsis plant metabolism in response to various stresses and nutritional cues. Plant Cell 2011, 23:1264-1271.

38. Leal N, Lastra R: Altered metabolism of tomato plants infected with tomato yellow mosaic virus. . Physiol Plant Pathol 1984, 24:1-7.

39. Jensen SG: Photosynthesis, respiration and other physiological relationships in barley infected with barley yellow dwarf virus. Phytopathology 1967, 58:204-208.

40. Berger S, Sinha AK, Roitsch T: Plant physiology meets phytopathology: plant primary metabolism and plant-pathogen interactions. $J$ Exp Bot 2007, 58:4019-4026. 
- Good review of how plant-pathogen interactions affect photosynthesis, sugar accumulation and sink metabolism

41. Bolton MD: Primary metabolism and plant defense--fuel for the fire. Mol Plant Microbe Interact 2009, 22:487-497.

-• This excellent review provides a comprehensive overview on changes in host physioloy and primary metabolism during incompatible plant-pathogen interactions and describes how plants recruit energy for the defense response.

42. Balint R, Cohen SS: The incorporation of radiolabeled polyamines and methionine into turnip yellow mosaic virus in protoplasts from infected plants. Virology 1985, 144:181-193.

43. Torget R, Lapi L, Cohen SS: Synthesis and accumulation of polyamines and Sadenosylmethionine in Chinese cabbage infected by turnip yellow mosaic virus. Biochem Biophys Res Commun 1979, 87:1132-1139.

44. Balint R, Cohen SS: The effects of dicyclohexylamine on polyamine biosynthesis and incorporation into turnip yellow mosaic virus in Chinese cabbage protoplasts infected in vitro. Virology 1985, 144:194-203.

45. Benicourt $\mathrm{C}$, Haenni AL: In vitro synthesis of turnip yellow mosaic virus coat protein in a wheat germ cell-free system. J Virol 1976, 20:196-202.

46. Morch MD, Benicourt C: Polyamines stimulate suppression of amber termination codons in vitro by normal tRNAs. Eur J Biochem 1980, 105:445-451.

47. Negrel J, Vallee JC, Martin C: Ornithine decarboxylase activity and the hypersensitive reaction of tobacco to tobacco mosaic virus in Nicotiana tabacum. Phytochemistry 1984, 23:2747-2751. 
48. Torrigiani P, Rabiti AL, Bortolotti C, Betti L, Marani F, Canova A, Bagni N: Polyamine synthesis and accumulation in the hypersensitive response to TMV in Nicotiana tabacum. New Phytol 1997, 135:467-473.

49. Rabiti AL, Betti L, Bortolotti C, Marini F, Canova A, Bagni N, Torrigiani P: Short-term polyamine response in TMV-inoculated hypersensitive and susceptible tobacco plants. New Phytol 1998, 139:549-553.

50. Marini F, Betti L, Scaramagli S, Biondi S, Torrigiani P: Polyamine metabolism is upregulated in response to tobacco mosaic virus in hypersensitive, but not in susceptible, tobacco. New Phytol 2001, 149:301-309.

- This works shows that in NN tobacco plants the response to TMV implies an increase in polyamine turnover with elevated biosynthetic enzyme activities and free and conjugated putrescine and sperimidine levels.

51. Yamakawa H, Kamada H, Satoh M, Ohashi Y: Spermine is a salicylate-independent endogenous inducer for both tobacco acidic pathogenesis-related proteins and resistance against tobacco mosaic virus infection. Plant Physiol 1998, 118:12131222.

52. Mitsuya Y, Takahashi Y, Berberich T, Miyazaki A, Matsumura H, Takahashi H, Terauchi $\mathrm{R}$, Kusano T: Spermine signaling plays a significant role in the defense response of Arabidopsis thaliana to cucumber mosaic virus. J Plant Physiol 2009, 166:626643.

53. Belles JM, Perez-Amador MA, Carbonell J, Conejero V: Correlation between Ornithine Decarboxylase and Putrescine in Tomato Plants Infected by Citrus Exocortis Viroid or Treated with Ethephon. Plant Physiol 1993, 102:933-937. 
54. Van Der Heijden MW, Carette JE, Reinhoud PJ, Haegi A, Bol JF: Alfalfa mosaic virus replicase proteins $\mathrm{P} 1$ and $\mathrm{P} 2$ interact and colocalize at the vacuolar membrane. $J$ Virol 2001, 75:1879-1887.

55. Schwartz M, Chen J, Janda M, Sullivan M, den Boon J, Ahlquist P: A positive-strand RNA virus replication complex parallels form and function of retrovirus capsids. Mol Cell 2002, 9:505-514.

56. Weber-Lotfi F, Dietrich A, Russo M, Rubino L: Mitochondrial targeting and membrane anchoring of a viral replicase in plant and yeast cells. J Virol 2002, 76:10485-10496.

57. Turner KA, Sit TL, Callaway AS, Allen NS, Lommel SA: Red clover necrotic mosaic virus replication proteins accumulate at the endoplasmic reticulum. Virology 2004, 320:276-290.

58. Rubino L, Weber-Lotfi F, Dietrich A, Stussi-Garaud C, Russo M: The open reading frame 1-encoded ('36K') protein of Carnation Italian ringspot virus localizes to mitochondria. J Gen Virol 2001, 82:29-34.

59. Heaton NS, Randall G: Multifaceted roles for lipids in viral infection. Trends Microbiol 2011, 19:368-375.

60. Ahlquist P, Noueiry AO, Lee WM, Kushner DB, Dye BT: Host factors in positivestrand RNA virus genome replication. $J$ Virol 2003, 77:8181-8186.

61. Dufourc EJ: Sterols and membrane dynamics. J Chem Biol 2008, 1:63-77.

62. Schneiter R, Kohlwein SD: Organelle structure, function, and inheritance in yeast: a role for fatty acid synthesis? Cell 1997, 88:431-434.

63. Jiang Y, Serviene E, Gal J, Panavas T, Nagy PD: Identification of essential host factors affecting tombusvirus RNA replication based on the yeast Tet promoters Hughes Collection. J Virol 2006, 80:7394-7404. 
67. Sharma M, Sasvari Z, Nagy PD: Inhibition of sterol biosynthesis reduces tombusvirus replication in yeast and plants. J Virol 2010, 84:2270-2281.

68. Lee WM, Ishikawa M, Ahlquist P: Mutation of host delta9 fatty acid desaturase inhibits brome mosaic virus RNA replication between template recognition and RNA synthesis. $J$ Virol 2001, 75:2097-2106.

69. Lee WM, Ahlquist P: Membrane synthesis, specific lipid requirements, and localized lipid composition changes associated with a positive-strand RNA virus RNA replication protein. $J$ Virol 2003, 77:12819-12828.

70. Rosenwasser S, Mausz MA, Schatz D, Sheyn U, Malitsky S, Aharoni A, Weinstock E, Tzfadia O, Ben-Dor S, Feldmesser E, et al.: Rewiring Host Lipid Metabolism by Large Viruses Determines the Fate of Emiliania huxleyi, a Bloom-Forming Alga in the Ocean. Plant Cell 2014, 26:2689-2707. 


\section{Figure legend:}

Figure 1. A simplified schematic representation of plant primary metabolism showing the major compounds that are altered in response to viral infections. Further details are given within the text and literature cited herein. ACP (acyl carrier protein), ER (endoplasmic reticulum), FA (fatty acids), LPA (lysophosphatidic acid), PA (phosphatidic acid). Glycolipids: DAG (diacylglycerol), DGDG (digalactosyl diacylglycerol), MGDG (monogalactosyl diacylglycerol), SQDG (sulfoquinovosyl diacylglycerol). Phospholipids: PC (phosphatidylcholine), PE (phosphatidylethanolamine), PI (phosphatidylinositol), PG (phosphatidylglycerol), 


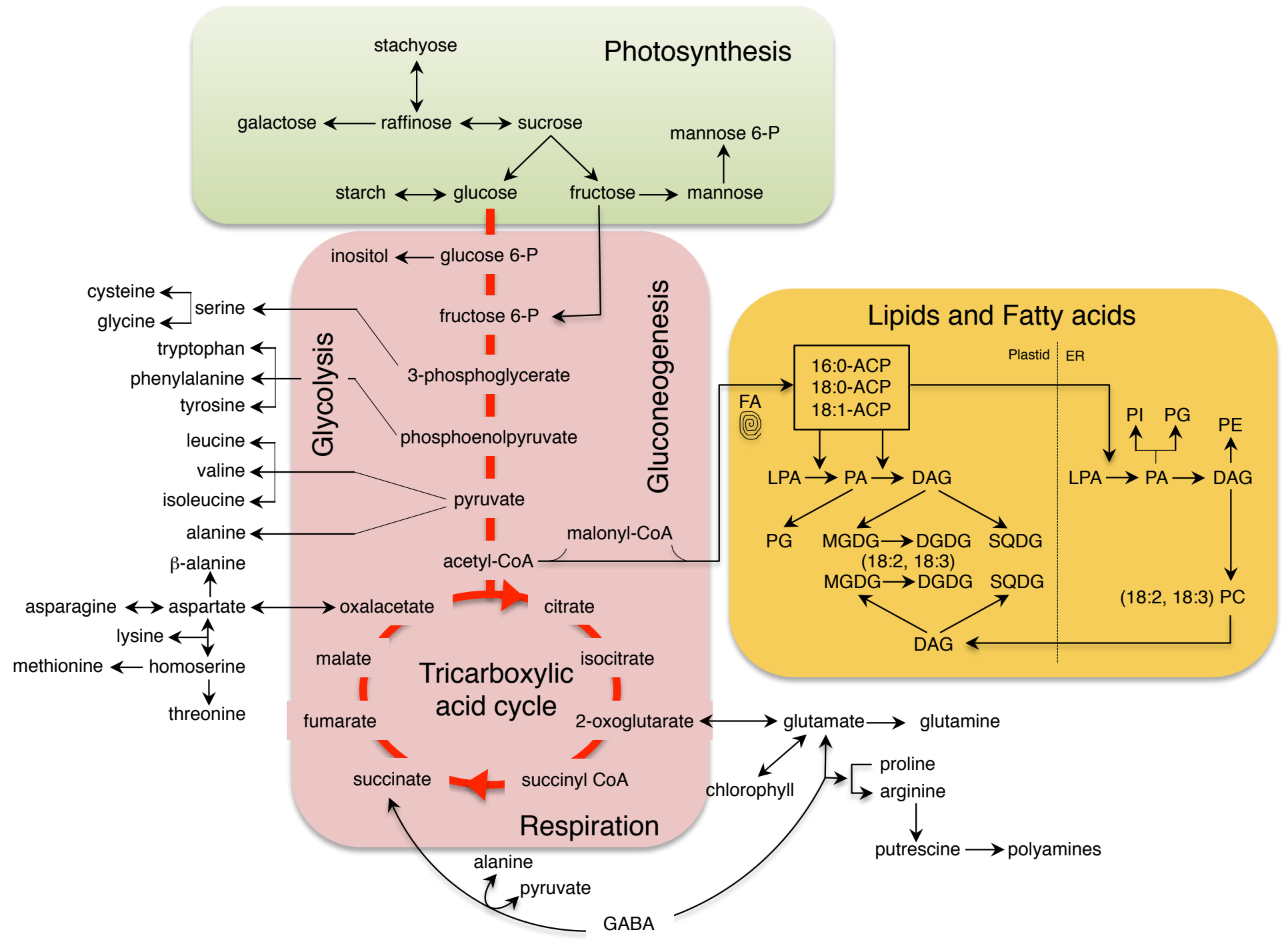

